\title{
Analisis Strategi 5C dalam Penyelesaian Kredit Bermasalah Bank Perkreditan Rakyat MD di Lamongan Jawa Timur
}

\author{
Kusuma Wijaya \\ email: kusumawijaya785@gmail.com \\ Fakultas Ekonomi Universitas Islam Lamongan
}

\begin{abstract}
This study aims to find out the 5Cs strategy adopted in the process of settlement of non-performing loans. Research data were analyzed with descriptive qualitative approach, and collected by studying documents, observation and interviews. These results indicated that the strategy had been implemented effectively in resolving loan problem showed by the decrease of loan problem number from year 2012 to 2014. Data obtained from the Peoples Credit Bank (PCB) MD in the provision of credit could not be separated from nonperforming loans. The factors are the failure of the debtor's business, bad characters, house transfering and death of the borrower. Credit settlement strategy undertaken by PCB MD were rescheduling, reconditioning and restructuring. Rescheduling was a change in credit terms concerning the payment schedule and time period, the amount of installment, and the grace period. Reconditioning (back requirements) was a partial or total changes in credit terms which was not limited to, changes in payment schedules, duration, and or other requirements, as long as no change plafon credit. And restructuring (or realignment) was including changes in conditions before credit terms: the addition of bank funds, conversion of all or part of the areas of interest into a new loan principal.
\end{abstract}

Keywords: 5Cs Strategy, loan settlement, non-performing loans

\section{PENDAHULUAN}

Bank merupakan suatu lembaga keuangan yaitu suatu badan usaha yang berfungsi sebagai perantara keuangan dari dua pihak, yakni pihak yang kekurangan dana dan membutuhkan dana. Bank menjadi lembaga perantara keuangan antara pihak yang kelebihan dana dan pihak yang membutuhkan dana.

Salah satu lembaga perantara keuangan itu adalah BPR MD Lamongan . BPR ini bertujuan membantu dan mendorong pertumbuhan perekonomian di segala bidang. Selain itu BPR MD Lamongan merupakan bank yang khususnya 
melayani masyarakat kecil di kabupaten Lamongan dan mewujudkan kredit kepada masyarakat.

Pemberian kredit mengandung suatu tingkat resiko tertentu dimana ada kemungkinan kredit yang tidak dapat ditagih. Walaupun berbagai antisipasi tersebut diatas sudah dilakukan tetapi masih saja mengalami kredit yang bermasalah. Hampir semua bank mengalami masalah kredit macet. Penelitian ini mendeskripsikan langkah yang ditempuh di BPR MD Lamongan dalam menyeleksi calon nasabah yang layak dan bagaimana mengungkap penyebab kredit bermasalah/macet, serta bagaimana penyelesaian kredit bermasalah tersebut.

Berdasarkan latar belakang masalah diatas, maka dapat dirumuskan masalah sebagai berikut:

1. Bagaimana Strategi 5C yang diterapkan BPR MD Lamongan dalam rangka menyelesaikan kredit bermasalah bagi nasabah ?

2. Apakah Strategi 5C tersebut telah efektif menyelesaikan kredit bermasalah pada BPR MD Lamongan ?

Tujuan Dan Penelitian ini adalah:

1. Untuk mengetahui bagaimana Strategi 5C yang diterapkan BPR MD Lamongan dalam rangka menyelesaikan kredit bermasalah bagi nasabah.

2. Untuk mengetahui apakah Strategi 5C tersebut telah efektif menyelesaikan kredit bermasalah pada BPR MD Lamongan.

\section{TINJAUAN PUSTAKA}

Ada beberapa penelitian sebelumnya yang berkaitan dengan industri perbankan di bidang perkreditan rakyat. Sujarwo, (2010), melakukan penelitian mengenai “Analisa Prosedur dan Pemberian Kredit pada Bank Rakyat Indonesia”. Permasalahan penelitian ini adalah prosedur pemberian kredit yang baik dapat mencegah timbulnya kredit bermasalah. Dimana kredit bermasalah dapat mempengaruhi kesehatan suatu bank. Hasil dari penelitian ini adalah untuk 
menilai dan mengetahui gambaran mengenai berjalannya proses perkreditan beserta personel-personel yang bertanggung jawab pada setiap prosesnya serta mengetahui prosedur pemberian kredit yang sesuai dengan prinsip kehati-hatian (prudential banking) dalam perkreditan untuk mendukung terciptanya praktekpraktek perkreditan yang sehat.

Fanani, (2010), melakukan penelitian tentang strategi penanganan kredit macet terhadap kelangsungan usaha pada BPR TAJ Pare, Kediri. Hasil penelitian ini adalah strategi yang telah ditempuh dalam upaya penanganan kredit macet guna kelangsungan hidup BPR adalah : 1)Manajemen puncak memberikan memberikan peluang bagi mereka yang berprestasi terutama berkaitan dengan kredit macet, 2)Meningkatkan sikap kehati-hatian dalam melakukan persetujuan atas kredit yang diajukan, 3)Meningkatkan pembinaan guna mengurangi tingkat kemacetan kredit, 4)Meningkatkan kepercayaan terhadap masyarakat.

Untuk menghindari atau memperkecil resiko tersebut, maka permohonan kredit harus dinilai oleh bank. Adapun syarat-syarat penilaianya dengan formula 5C adalah, Character, Capacity, Capital, Collateral, dan Condition of economy. Dengan dipenuhinya syarat-syarat penilaian tersebut maka kredit yang tidak dapat ditagih dapat diminimalisasikan.

The Five C's Of Credit Analysis (Penjelasan pasal 8 (1) UU No. 7/1992 tentang perbankan sebagaimana telah diubah dengan UU No. 10/1998 adalah sebagai berikut :

a. Character adalah kepribadian dan moral calon debitur yang selalu harus teliti secara seksama, terutama dalam menghadapi calon debitur yang baru.

b. Capacity adalah kemampuan calon debitur dalam membayar kredit dilihat dari mengelola bisnisnya.

c. Capital adalah modal yang dimiliki debitur pada waktu permohonan kredit yang diajukan

d. Collateral adalah agunan atau jaminan tambahan berupa benda atau orang (personal guarrante)yang dapat diberikan oleh calon debitur 
e. Condition of economy adalah keadaan ekonomi sosial dan politik yang ada sekarang dan prediksi untuk masa yang akan datang

Tabel 1

Kriteria Kredit Bermasalah

\begin{tabular}{|l|l|l|}
\hline Kriteria Kredit & \multicolumn{1}{|c|}{ Angsuran } & \multicolumn{1}{c|}{ Bunga } \\
\hline Lancar & Tidak pernah nunggak & Tidak pernah nunggak \\
\hline $\begin{array}{l}\text { Dalam } \\
\text { Kengawasan }\end{array}$ & $\begin{array}{l}\text { Lebih dari 30 hari setelah } \\
\text { tanggal jatuh tempo. }\end{array}$ & $\begin{array}{l}\text { Lebih dari 30 hari setelah } \\
\text { tanggal jatuh tempo. }\end{array}$ \\
\hline Kurang Lancar & $\begin{array}{l}\text { Pembayaran lebih 90 hari } \\
\text { atau lebih setelah tanggal } \\
\text { jatuh tempo. }\end{array}$ & $\begin{array}{l}\text { Pembayaran lebih 90 hari atau } \\
\text { lebih setelah tanggal jatuh } \\
\text { tempo. }\end{array}$ \\
\hline Diragukan & $\begin{array}{l}\text { Pembayaran lebih 120 hari } \\
\text { atau lebih setelah tanggal } \\
\text { jatuh tempo dan perusahaan } \\
\text { tidak mampu membayar }\end{array}$ & $\begin{array}{l}\text { Pembayaran lebih 120 hari atau } \\
\text { lebih setelah tanggal jatuh } \\
\text { tempo dan perusahaan tidak } \\
\text { mampu membayar }\end{array}$ \\
\hline Macet & $\begin{array}{l}\text { Nasabah tidak melakukan } \\
\text { pembayaran lebih dari 120 } \\
\text { hari setelah atnggal jatuh } \\
\text { tempo dan/atau nasabah tidak } \\
\text { mampu membayar. }\end{array}$ & $\begin{array}{l}\text { Nasabah tidak melakukan } \\
\text { pembayaran lebih dari 120 hari } \\
\text { setelah atnggal jatuh tempo } \\
\text { dan/atau nasabah tidak mampu } \\
\text { membayar. }\end{array}$ \\
\hline
\end{tabular}

Sumber : PSAK 31 Revisi 2001

Variabel Penelitian dalam penelitian ini adalah variabel strategi 5C dalam penyelesaian kredit bermasalah dan kredit bermasalah pada BPR MD.

\section{METODE PENELITIAN}

Penelitian ini menggunakan pendekatan deskriptif kualitatif, yaitu paradigma penelitian yang menekankan pada pemahaman mengenai masalahmasalah dalam kehidupan social berdasarkan kondisi realitas atau natural setting yang holistic, kompleks dan rinci. (Indiantoro, et al. 1999:12).

Populasi dalam penelitian ini adalah kredit bermasalah pada BPR MD Lamongan. Sedangkan teknik penarikan sampel adalah sebagian dari populasi itu 
dan yang menjadi sampel adalah kredit bermasalah pada tahun 2013-2016 di BPR MD Lamongan.

Metode pengumpulan data menggunakan metode wawancara. Pengumpulan data melalui tanya jawab scara lisan dengan sumber data yang bersangkutan yaitu Direktur utama BPR MD Lamongan Bapak Drs. MAF secara langsung tanpa dan dengan daftar pertanyaan. Observasi yaitu pengumpulan data secara langsung dari obyek penelitian melalui pengamatan, dicatat dan direduksi kemudian disajikan secara sistematis untuk mengambarkan obyek yang diteliti. Dokumentasi yaitu mengumpulkan data tentang keadaan atau kegiatan yang terjadi. Dalam penelitian ini data yang digunakan yaitu tentang pendirian, struktur organisasi, prosedur pemberian kredit, permasalahan kredit dan penanganan kredit.

\section{HASIL DAN PEMBAHASAN PENELITIAN}

Di bawah ini adalah data jabatan pekerjaan pegawai BPR MD lamongan.

\section{Tabel 2}

\section{Jenis Jabatan Pekerjaan BPR MD Lamongan}

\begin{tabular}{|c|l|c|c|}
\hline No & \multicolumn{1}{|c|}{ Jabatan } & Jumlah & Keterangan \\
\hline 1 & Direktur & 1 & Pegawai BPR \\
\hline 2 & Satuan Pengawas Intern (SPI) & 1 & Pegawai BPR \\
\hline 3 & Kepala Bagian & 1 & Pegawai BPR \\
\hline 4 & Kepala Kantor & 3 & Pegawai BPR \\
\hline 5 & CS & 1 & Pegawai BPR \\
\hline 6 & Head Teller & 1 & Pegawai BPR \\
\hline 7 & Pembukuan & 5 & Pegawai BPR \\
\hline 8 & Teller & 1 & Pegawai BPR \\
\hline 9 & AO & 4 & Pegawai BPR \\
\hline 10 & Penagihan & 1 & Pegawai BPR \\
\hline 11 & Adm. Kredit & 1 & Pegawai BPR \\
\hline 12 & Adm. Dana & 1 & Pegawai BPR \\
\hline 13 & Ofice & 23 & Pegawai BPR \\
\hline 14 & Satpam & 1 & \\
\hline \multicolumn{2}{|c|}{ Jumlah } &
\end{tabular}

Sumber data : PT. BPR MD Lamongan (Per April 2015) 
Selanjutnya tabel dibawah ini adalah tingkat pendidikan pegawai PT. BPR MD.

Tabel 3

Tingkat Pendidikan Pegawai

\begin{tabular}{|c|c|c|}
\hline No & Tingkat Pendidikan & Jumlah \\
\hline 1 & S1 & 10 \\
\hline 2 & D3 & 1 \\
\hline 3 & SMU/SMK & 11 \\
\hline 4 & SMP & 1 \\
\hline \multicolumn{2}{|c|}{ Jumlah } & 23 \\
\hline
\end{tabular}

Sumber data : PT. BPR MD Lamongan (Per April 2015)

Berikut tabel dibawah ini adalah kriteria pengelompokan berdasarkan kelancaran atau keadaan.

\section{Tabel 4}

Pengelompokan Kredit berdasarkan Kolektabilitas Pengembalian

\begin{tabular}{|c|l|l|l|}
\hline No & Kolektabilitas & Jangka Waktu Kredit & $\begin{array}{l}\text { Keterangan Kelancaran } \\
\text { Pengembalian }\end{array}$ \\
\hline 1 & Lancar & 1 bulan & $<1$ bulan \\
\hline & & $1-3$ bulan & $<3$ bulan \\
\hline & & 4 bulan/lebih & $<6$ bulan \\
\hline 2 & Kurang Lancar & Tanpa angsuran & Sebelum jatuh tempo \\
\hline & & 4 bulan/lebih & $<1$ bulan $<3$ bulan \\
\hline 3 & Diragukan & $<3$ bulan & $>3$ bulan $<6$ bulan \\
\hline & & $\begin{array}{l}\text { T5\% dari saldo kredit }+ \\
\text { bunga }\end{array}$ & $\begin{array}{l}\text { Tidak termasuk lancar dan } \\
\text { kurang lancar. }\end{array}$ \\
\hline & & $\begin{array}{l}\text { Agunan minimum dapat diselamatkan. } \\
\text { dari kewajiban }\end{array}$ & $\begin{array}{l}\text { Kredit tidak dapat } \\
\text { diselamatkan. }\end{array}$ \\
\hline 4 & Macet & $\begin{array}{l}\text { Tidak termasuk kriteria } \\
\text { lancar, kurang lancar, } \\
\text { diragukan. }\end{array}$ \\
\hline & & $\begin{array}{l}>21 \text { bulan sejak kredit } \\
\text { digolongkan }\end{array}$ & $\begin{array}{l}\text { Belum ada pelunasan / } \\
\text { penyelamatan }\end{array}$ \\
\hline
\end{tabular}




\begin{tabular}{|l|l|l|l|}
\hline No & Kolektabilitas & Jangka Waktu Kredit & $\begin{array}{l}\text { Keterangan Kelancaran } \\
\text { Pengembalian }\end{array}$ \\
\hline & & $\begin{array}{l}\text { Penyelesaian kredit } \\
\text { diserahkan ke pengadilan } \\
\text { negeri, Badan Urusan } \\
\text { Negara bank ke perusahaan } \\
\text { asuransi kredit. }\end{array}$ \\
\hline
\end{tabular}

Data yang didapat dari BPR MD terdapat informasi mengenai penyebab kredit bermasalah. Ada penyebab kredit bermasalah/macet karena gagal usaha, karakter jelak, pindah alamat dan karena meninggal dunia.

Tabel 5

Penyebab Kredit Bermasalah / Macet Tahun : 2012 - 2014

\begin{tabular}{|c|c|c|c|c|c|}
\hline \multirow{2}{*}{ No } & \multirow{2}{*}{ Tahun } & \multicolumn{4}{|c|}{ Jumlah Nasabah } \\
\cline { 3 - 6 } & & Gagal Usaha & Karakter Jelek & $\begin{array}{c}\text { Pindah } \\
\text { Alamat }\end{array}$ & Meninggal \\
\hline 1 & 2012 & 910 & 405 & 168 & 85 \\
\hline 2 & 2013 & 720 & 350 & 120 & 105 \\
\hline 3 & 2014 & 605 & 270 & 88 & 45 \\
\hline
\end{tabular}

Sumber data : PT. BPR MD Lamongan

Dari data diatas dapat diketahui kegagalan usaha yang menjadi penyebab kredit macet, karakter jelek, perpindahan alamat dan meninggal dunia yang semakin menurun.

Upaya kolektibilitas kredit dilakukan secara hati-hati. Berikut tabel di bawah ini adalah data upaya kolektibilitas kredit dari BPR MD Lamongan. 
Tabel 6

Kolektibilitas Kredit Tahun 2012-2014

\begin{tabular}{|c|c|c|c|c|c|}
\hline \multirow{2}{*}{ No } & \multirow{2}{*}{ Tahun } & \multicolumn{4}{|c|}{ Nasabah } \\
\cline { 3 - 6 } & Lancar & $\begin{array}{c}\text { Kurang } \\
\text { Lancar }\end{array}$ & Diragukan & Macet \\
\hline 1 & 2012 & 7.900 & 358 & 215 & 1.530 \\
\hline 2 & 2013 & 8.739 & 206 & 182 & 1.171 \\
\hline 3 & 2014 & 9.423 & 102 & 129 & 985 \\
\hline
\end{tabular}

Sumber data : BPR MD Lamongan.

Dari tabel diatas dapat dilihat bahwa pada tahun 2012 - 2014 terdapat adanya posisi nasabah dalam pengembalian kreditnya :

1. Lancar : Mengalami kenaikan jumlah

2. Kurang Lancar : Mengalami penurunan jumlah

3. Diragukan : Mengalami penurunan jumlah

4. Macet : Mengalami penurunan jumlah

Bentuk atau cara penyelesaian kredit macet atau bermasalah di BPR MD Lamongan disajikan dalam tabel berikut ini :

Tabel 7

Penyelesaian Kredit Bermasalah di BPR MD Lamongan

\begin{tabular}{|c|c|}
\hline Kriteria & Cara Penyelesaian Kredit Macet / Bermasalah \\
\hline Kurang Lancar & $\begin{array}{l}\text { Tindakan analisa usaha: } \\
\text { a. Melakukan peninjauan langsung ke lokasi (on the } \\
\text { spot) untuk melihat realita kondisi dan } \\
\text { perkembangan usaha debitur. } \\
\text { b. Melakukan tindakan trade checking pada pihak } \\
\text { supplier dan langganan debitur. } \\
\text { c. Melakukan interview secara langsung pada pihak } \\
\text { debitur untuk mengetahui sebab-sebab terjadinya } \\
\text { gejala-gejala kredit bermasalah/macet. } \\
\text { d. Melakukan bank checking pada Bank Indonesia }\end{array}$ \\
\hline
\end{tabular}




\begin{tabular}{|c|c|}
\hline Kriteria & Cara Penyelesaian Kredit Macet / Bermasalah \\
\hline & $\begin{array}{l}\text { untuk mengetahui posisi kolektibilitas kredit debitur } \\
\text { di bank lain. } \\
\text { e. Melakukan review atas perkembangan nilai pasar } \\
\text { wajar jaminan kredit. } \\
\text { Tindakan penyelamatan Bank : } \\
\text { a. Memberikan grace period pembayaran bunga kepada } \\
\text { debitur tersebut untuk jangka waktu tertentu. } \\
\text { b. Bila diperlukan, pihak Bank akan memberikan kredit } \\
\text { baru tambahan jangka waktu tertentu. } \\
\text { c. Menurunkan beban tingkat suku bunga pinjaman } \\
\text { debitur tersebut pada tingkat yang wajar. }\end{array}$ \\
\hline Diragukan & $\begin{array}{l}\text { a. Meminta kepada debitur tersebut untuk menjual } \\
\text { assetnya sebagai sumber pelunasan hutangnya. } \\
\text { b. Menekan debitur tersebut agar menjual jaminan yang } \\
\text { diserahkan Bank untuk melunasi kewajibannya. } \\
\text { c. Pihak BPR MD Lamongan melalui staf karyawannya } \\
\text { membantu debitur dalam menjual asset dan jaminan } \\
\text { kreditnya pada masyarakat untuk melunasi } \\
\text { hutangnya. }\end{array}$ \\
\hline Macet Total & $\begin{array}{l}\text { a. Melakukan negosiasi dengan pihak debitur agar } \\
\text { menyerahkan jaminan kredit secara baik-baik untuk } \\
\text { melunasi total hutang pokok dan bunga, bila jaminan } \\
\text { kredit cukup mengcover total kewajibannya. } \\
\text { b. Melakukan negosiasi dengan pihak debitur agar } \\
\text { menyerahkan jaminan kredit secara baik-baik untuk } \\
\text { melunasi total hutang pokok dan bunga, bila jaminan } \\
\text { kredit tidak mengcover dan bersangkutan tidak } \\
\text { mempunyai kekayaan lain untuk membayar } \\
\text { kekurangan dengan catatan minimal kembali pokok } \\
\text { pinjaman dan diberikan keringanan pengurangan } \\
\text { biaya bunga. } \\
\text { c. Bila debitur tidak menunjukkan kemauan baik untuk } \\
\text { menyelesaikan kredit bermasalah secara baik-baik } \\
\text { maka BPR MD Lamongan akan menempuh jalur } \\
\text { hukum sebagai jalan akhir sampai eksekusi sita } \\
\text { jaminan. Dalam perkara ini, bila terjadi kekurangan } \\
\text { dalam pembayaran total hutang dan debitur masih } \\
\text { mempunyai kekayaan lain maka akan melakukan } \\
\text { gugatan permohonan sita jaminan atas asset lain } \\
\text { yang dimiliki debitur tersebut. }\end{array}$ \\
\hline
\end{tabular}


Laporan kredit bermasalah di BPR MD Lamongan disajikan dalam tabel di bawah ini :

\section{Tabel 8}

\section{Laporan kredit PT. BPR MD Lamongan (2012-2014)}

Tahun 2012

(Dalam Ribuan)

\begin{tabular}{|c|l|c|c|c|c|c|}
\hline NO & \multicolumn{1}{|c|}{ KETERANGAN } & L & KL & D & M & Jumlah \\
\hline 1 & Penempatan pada bank lain & 1.129 .171 & & & & 1.129 .171 \\
\hline 2 & Kredit yang diberikan & & & & & \\
\hline a & Kepada pihak terkait & 26.913 & & & & 26.913 \\
\hline b & Kepada pihak tidak terkait & 7.708 .850 & 53.948 & 53.072 & 292.715 & 8.108 .585 \\
\hline 3 & Jumlah aktiva produktif & 8.864 .934 & 53.948 & 53.072 & 292.715 & 9.264 .669 \\
\hline
\end{tabular}

Sumber data : PT. BPR MD Lamongan

Tahun 2013

(Dalam Ribuan)

\begin{tabular}{|c|l|c|c|c|c|c|}
\hline NO & \multicolumn{1}{|c|}{ KETERANGAN } & L & KL & D & M & Jumlah \\
\hline 1 & Penempatan pada bank lain & 1.705 .696 & & & & 1.705 .696 \\
\hline 2 & Kredit yang diberikan & & & & & \\
\hline a & Kepada pihak terkait & 22.891 & & & & 22.891 \\
\hline b & Kepada pihak tidak terkait & 6.244 .576 & 32.658 & 63.309 & 373.655 & 6.714 .198 \\
\hline 3 & Jumlah aktiva produktif & 7.973 .163 & 32.658 & 63.309 & 373.655 & 8.442 .785 \\
\hline
\end{tabular}

Sumber data : PT. BPR MD Lamongan

Tahun 2014

(Dalam Ribuan)

\begin{tabular}{|c|l|c|c|c|c|c|}
\hline NO & \multicolumn{1}{|c|}{ KETERANGAN } & L & KL & D & M & Jumlah \\
\hline 1 & Penempatan pada bank lain & 1.332 .828 & & & & 1.332 .828 \\
\hline 2 & Kredit yang diberikan & & & & & \\
\hline a & Kepada pihak terkait & 56.060 & & & & 56.060 \\
\hline b & Kepada pihak tidak terkait & 7.766 .876 & 27.995 & 59.614 & 294.537 & 8.149 .022 \\
\hline 3 & Jumlah aktiva produktif & 9.155 .764 & 27.995 & 59.614 & 294.537 & 9.537 .910 \\
\hline
\end{tabular}

Sumber data : PT. BPR MD Lamongan

Dalam hal ini yang paling mempengaruhi kredit bermasalah pada PT. BPR MD Lamongan adalah condition of economiy (kondisi ekonomi), seperti gagal usaha dan character (kepribadian/moral), seperti karakter jelek nasabah. 
Dengan ini dapat di simpulkan bahwa PT. BPR X Lamongan telah efektif menerapkan strategi 5C dalam menyelesaikan kredit bermasalah dapat dilihat pada laporan kredit yang bermasalah (Bad Debt Report) mulai tahun 2012-2014 mengalami penurunan, antara lain :

1. Character (Karakter): Meneliti sifat dan watak pribadi calon nasabah.

2. Capacity (Kemampuan) : Melihat kemampuan calon nasabah dalam mengelola usahanya.

3. Capital (Modal) : Mengecek dan menganalisa modal calon nasabah untuk mengetahui kemampuan melunasi hutang

4. Collateral (Jaminan) : Menilai jaminan calon nasabah

5. Condition of economy (Kondisi ekonomi) : Usaha calon nasabah masih memungkinkan dapat dikembangkan dan bermanfaat.

Bentuk tolak ukur pemberian kredit bermasalah di BPR MD Lamongan disajikan dalam tabel di bawah ini :

\section{Tabel 9}

Tolak ukur pemberian kredit pada PT. BPR MD Lamongan

\begin{tabular}{|l|l|}
\hline $\begin{array}{c}\text { Prinsip-prinsip } \\
\text { Pemberian Kredit } \\
\text { (prinsip 5C) }\end{array}$ & \multicolumn{1}{c|}{ Tolak Ukur pada PT. BPR MD Lamongan } \\
\hline 1. Character & $\begin{array}{l}\text { 1. Dilihat dari aplikasi permohonan kredit yang dibuat oleh } \\
\text { calon debitur } \\
\text { 2. Dilihat dari watak/pribadi debitur }\end{array}$ \\
\hline 2. Capacity & $\begin{array}{l}\text { Dilihat dari usaha yang dijalankan oleh calon debitur } \\
\text { apakah usaha tersebut mempunyai prospektif yang baik. }\end{array}$ \\
\hline 3. Capital & $\begin{array}{l}\text { Dengan melihat prospek usaha dan perputaran modal calon } \\
\text { debitur. }\end{array}$ \\
\hline 4. Collateral & $\begin{array}{l}\text { Dilihat dari agunan dengan jumlah pinjaman. } \\
\text { Misalnya : Dilihat dari sertifikat tanah dan bangunan. } \\
\text { Transaksi harga jual tanah dan bangunan ini harus melebihi } \\
\text { dari jumlah yang diberikan untuk kredit konsumtif. }\end{array}$ \\
\hline 5. Condition & $\begin{array}{l}\text { Dilihat dari usaha calon debitur yang masih bisa } \\
\text { dikembangkan dan bermanfaat ( Going Concern ). }\end{array}$ \\
\hline
\end{tabular}

Sumber : PT. BPR MD Lamongan 
Dari data yang diperoleh dari BPR MD Lamongan dalam pemberian kreditnya tak lepas dari kredit bermasalah. Adapun faktor-faktor yang menimbulkan masalah adalah kegagalan usaha debitur, karakter pemilik usaha yang jelek, berpindah rumah dan karena meninggal dunia. Strategi penyelesaian kredit yang dilakukan oleh BPR MD Lamongan adalah pertama : membuat rescheduling (penjadwalan kembali) yaitu perubahan syarat kredit yaitu yang menyangkut jadwal pembayaran dan jangka waktu, membuat tinjauan besarnya angsuran, dan lama masa tenggang. Kedua : membuat reconditioning (persyaratan kembali) yaitu perubahan sebagian atau keseluruan syarat-syarat kredit yang tidak terbatas pada perubahan jadwal pembayaran, jangka waktu, dan atau persyaratan lainnya, sepanjang tidak merubah plafon kredit, dan ketiga : melakukan restructuring (penataan kembali) yaitu perubahan syarat-syarat kredit yang menyangkut : penambahan dana bank, konversi seluruh atau sebagian tunggakan bunga menjadi pokok kredit baru.

\section{KESIMPULAN}

Berdasarkan pembahasan penelitian yang penulis lakukan dan analisa pembahasan masalah pada BPR MD Lamongan, yang telah dikemukakan pada bab-bab sebelumnya, maka diambil kesimpulan sebagai berikut :

1. Prosedur pemberian kredit yang dilakukan oleh BPR MD Lamongan adalah permohonan kredit oleh debitur, penelitian berkas, pencairan informasi bank, kunjungan lapangan, dan analisis penilaian kredit. Bila disetujui maka akan dilakukan perjanjian atau pengikatan agunan. Setelah itu dilakukan pengawasan kredit atau pembinaan direktur.

2. Untuk mengatasi kredit bermasalah perlu dilakukan upaya membuat rescheduling (penjadwalan kembali), membuat reconditioning (persyaratan kembali), dan melakukan restructuring (penataan kembali).

3. Dengan ini dapat disimpulkan bahwa PT. BPR MD Lamongan telah efektif menerapkan strategi 5C dalam menyelesaikan kredit bermasalah dapat dilihat 
pada laporan kredit bermasalah/macet tahun 2012-2014 mengalami penurunan.

4. Mensurvey dan menganalisa kemampuan/modal calon nasabah secara teliti agar kredit bermasalah/macet dapat di minimalisir.

\section{SARAN}

Beberapa saran yang dapat dikemukakan sebagai bahan pertimbangan bagi BPR MD Lamongan, untuk memperkecil adanya resiko kredit yang terjadi antara lain :

1. BPR MD Lamongan hendaknya dalam Prosedur pemberian kredit harus lebih teliti yaitu melakukan on the spot (peninjauan ke lapangan) sehingga dapat mengetahui kemampuan debitur dalam mengembalikan kreditnya.

2. BPR MD Lamongan hendaknya tidak menutup-nutupi adanya kredit bermasalah dan segera mengatasinya dengan menyusun daftar kolektibilitas kredit, melakukan peringatan secara tegas dan cepat kepada debitur yang dalam pengembalian kreditnya tidak lancar.

\section{DAFTAR PUSTAKA}

Denda, W. 2005. Manajemen Perbankan. Jakarta. Ghalia Indonesia, edisi kedua.

Djumhana, M. 1993. Hukum Perbankan di Indonesia. Bandung. PT, Citra Aditya Bakti.

Ikatan Akuntansi Indonesia. 2001. Pernyataan Standart Akuntansi Keuangan, Revisi 2001. Jakarta. PT, Salemba Empat.

Indrianto, N. dan Supomo, B. 1999. Metodologi Penelitian Bisnis. Yogyakarta. BPFE, edisi Pertama.

Kasmir. 2001. Manajemen Perbankan. Jakarta. PT, Gramedia Pustaka Utama. 
Nur, Y. Yulianti. 1993. Penerapan Keterikatan Bank Indonesia Tentang Capital Adequency Ratio, Loan To Deposit Ratio dan Legal Lending Limit Sebagai Salah Satu Tolak Ukur Go Publik di Indonesia. Universitas Airlangga Surabaya.

Peraturan Pemerintah RI No. 70 Tahun 1992

Peraturan Pemerintah RI No. 71 Tahun 1992, Pasal 4 Butir 1.

Supramono, G. 1995. Perbankan dan Masalah Kredit Suatu Tinjauan Yuridis. Jakarta. Djambatan.

Sutojo, S. 1995. Analisa Kredit Bank Umum. Jakarta. PT, Pustaka Bina Binaman Presindo.

Tje’Aman, E., Putra. 1985. Kredit Perbankan Suatu Tinjauan Yuridis. Yogyakarta. Liberty.

Undang-undang Perbankan No. 7 Tahun 1992.

Undang-undang Perbankan Pasal 8 No. 10 Tahun 1998.

Yulianti, A. 1998. Pengaruh Legal Lending Limit terhadap Kredit Macet Pada Bank-Bank Pemerintah. Universitas Airlangga Surabaya. 